\title{
Study on Influence of Enterprise Competence, Trust Relationship, and System Environment on the Autonomous Upgrade of Enterprise
}

\author{
Jinrong $\mathrm{Yu}$ \\ Nanchang Hangkong University, \\ Nanchang, China
}

\begin{abstract}
In this paper, we take 316 questionnaires from OEM enterprises in Suzhou, Wuxi, Zhongshan, Shenzhen, Huizhou and other places as the research samples. By SPSS software, this paper comprehensively uses reliability, validity test, regulating effect, exploratory factor analysis and other methods to empirically analyze the influence of the foundries' technology power, market power and brand power on their enterprise functional upgrading. This study puts forward the upgrading strategy of OEM enterprises from the perspective of cultivating the "three powers" of the OEM enterprise's technology power, market power and brand power.
\end{abstract}

Keywords-Enterprise competence; Trust relationship; System environment; Enterprise upgrade

\section{INTRODUCTION}

Domestic and foreign scholars have conducted a great deal of theoretical and empirical research on how enterprise's competence affects its upgrading, providing theoretical support and empirical reference for the upgrading of enterprise. In the new globalized environment, what is the composition of the competence of OEM, how the system environment of the enterprise affects the conversion of the enterprise's competence and then the upgrading of the enterprise, these questions are pending for further studies. To better understand the inherent mechanism of the enterprise's competence to affect its upgrading, it is necessary to study the regulatory role of the trust relationship and the system environment, which is of important realistic significance for the enterprise's self-construction and competence selection and the realization of enterprise upgrading. This study takes trust relationship and system environment as the regulatory variables between enterprise competence and its upgrading to test the regulating effect of the environmental variables.

\section{LITERATURE REVIEW AND RESEARCH ASSUMPTIONS}

Kaplinsky [1] argues that enterprises in different positions of the value chain have the corresponding power. The power organization coordinates the value creation activities of the enterprises in the value chain and carries out the value distribution. Technical competence and brand competence are the main sources of market power concentration of the world leading enterprises, as well as the decisive factors in determining the value distribution of the global value chain. The key to the upgrading of OEM enterprises in developing countries embedded in the global value chain lies in their absorptive capacity and learning speed, changing timing, position, scale and growth opportunities in the global value chain [2]. According to the previous explanation and analysis of the theoretical basis of the model, combined with the development characteristics of OEM enterprises, this study takes technology power, market power and brand power these three kinds of power as the main contents for the construction of OEM enterprises competence, and further studies how these powers affect the upgrading of OEM enterprises.

\section{A. The hypothetical relationship between technology power and OEM enterprise upgrading}

The technology power is an important driving force for the upgrading of OEM enterprises. This study considers that there are two aspects in the technology power of OEM enterprise upgrading: technical power and technical ability. In the global value chain, foundries with more advanced technological experience, professional knowledge and innovative abilities are more depended technically and have relatively stronger technical power; and their technical power grows with the identification and application of technical opportunities [3]. Under full competition situation, the technology acquired by foundries can obtain short-term market power but would disappear soon [4]. Patents have created great monopoly power in the industry [5], which gives power to multinational corporations in the value chain and causes foundries to enter the high-end barriers and catch-up traps in the value chain. The technical standards are affecting the operational efficiency of the enterprises, and their setters' mandatory intervention of the controller has affected the products and the upgrading process of the enterprises [6]. Based on above analysis, this paper presents the following hypothesis:

$\mathrm{H} 1$ : the intensity of technology power of the OEM is positively correlated to its functional upgrading.

\section{B. The assumption of market power and OEM enterprise upgrade}

The research on the OEM enterprises' market power is different from the pricing behavior of the traditional monopoly enterprises. OEM enterprises can also form some market forces in the market, so as to obtain more profits. An enterprise with market power can change the sales of its competitors by changing prices or promotions [7]. Liu Zhibiao [8] thinks that the upgrade of OEM enterprises will encounter the dual blocks of the technological forces possessed by the 
multinational companies in developed countries and the market power of international buyers. OEM enterprises may choose to form a domestic market value chain based on the huge domestic market, establish a "regional" value chain and cultivate domestic market power. According to above analysis, this paper presents the following hypothesis:

$\mathrm{H} 2$ : the intensity of market power of the OEM is positively correlated with its functional upgrading.

\section{The hypothetical relationship between the brand power and OEM enterprise functional upgrading}

Customer-based brand power reflects the values, power structure, and long-term market dominance of technology excellence. The financial value of a brand depends on its "brand strength," namely its strength of customer franchise [9] It's because small businesses must often rely on networks and word-of-mouth to build strong, profitable and unique associations [10]. Through branding, the foundries can create, cultivate and innovate their market assets, foster the brand awareness and consumer brand equity such as reputation to enhance and control the trust of customers, as well as create profits for the foundries. Based on above analysis, this paper presents the following hypothesis:

H3: the intensity of brand power of OEM is positively correlated with its functional upgrading.

\section{The regulatory role of trust relationship}

According to the social embeddedness theory, trust is the foundation for the foundries to cooperate with other enterprises and members. Mutual trust can reduce the constraints of both parties and is also the key factor for the growth of the OEM enterprises. McAllister [11] divided trust into emotional trust and cognitive trust. Nooteboom [12] divided trust into motivated trust and non-self-interested trust, which is the connection and dependence established by long-term cooperation between the two parties. Stronger trust relationship can reduce cost in the profit, recognition, power and other aspects that brought by sharing, it can meet the psychological or exchange expectations of both parties [13], as well as gradually establish the related power scope of the OEM enterprises. Based on above analysis, this paper presents following hypotheses:

H4: The role of OEM's technology power on its functional upgrading is regulated by the trust relationship, the better the trust relationship, the higher level of its technology power, the more conducive to promote the functional upgrading of the OEM enterprises.

H5: The role of OEM's market power on its functional upgrading is regulated by the trust relationship, the better the trust relationship, the higher level of its market power, the more conducive to promote the functional upgrading of the OEM enterprises

H6: The role of OEM's brand power on its functional upgrading is regulated by the trust relationship, the better the trust relationship, the higher level of its brand power, the more conducive to promote the functional upgrading of the OEM enterprises.

\section{$E$. The regulatory role of the system environment}

The system environment in which the foundries are situated is an important factor affecting the strategic decision-making of OEM enterprises. The system environment formed by relevant systems such as the innovation system of the country (region), innovation policies, science and technology system, intellectual property protection system, contract system and industry standards etc. The system environment is conducive to promoting more R\&D investment in foundries, stimulating the entrepreneurs' innovation spirit and realizing technological upgrading of the foundries. The market environmental factors are important factors in forming a favorable environment for the market and brand promotion of the foundries, including formal system environment such as RMB appreciation, incentive policies, tax advantages, trade barriers, property rights system, subsidy system, drawback on export tax, financing system, market access system, antitrust system, etc, and informal system environment such as rights, contracts, ethics and moral awareness [14], etc. Based on above analysis, this paper presents the following hypotheses:

H7: The role of OEM's technology power on its functional upgrading is regulated by the system environment, the better the system environment, and the higher level of its technology power, the more conducive to promote the functional upgrading of the OEM enterprises.

H8: The role of OEM's market power on its functional upgrading is regulated by the system environment, the better the system environment, the higher level of its market power, the more conducive to promote the functional upgrading of the OEM enterprises.

H9: The role of OEM's brand power on its functional upgrading is regulated by the system environment, the better the system environment, the higher level of its brand power, the more conducive to promote the functional upgrading of the OEM enterprises.

To summarize above assumptions, the theoretical framework of this study is shown in Fig. 1.

\section{RESEARCH DESIGN AND MethodS}

\section{A. Sample selection and questionnaire design}

The research objects of the questionnaires are also the research objects of this study, namely OEM enterprises with a self-willingness of upgrading which have accumulated certain resources and abilities, and are preparing for functional upgrading. These enterprises mainly engaged or are engaging in OEM manufacturing; the types of these enterprises include state-owned companies, Sino-foreign joint ventures, small and medium-sized enterprises. Finally, there are 322 returned questionnaires, after deleting the ones with incorrect answers, or incomplete information, or unmatched company type, we got 316 valid questionnaires in the end, and the qualification rate of the returned questionnaires was $91.68 \%$. 


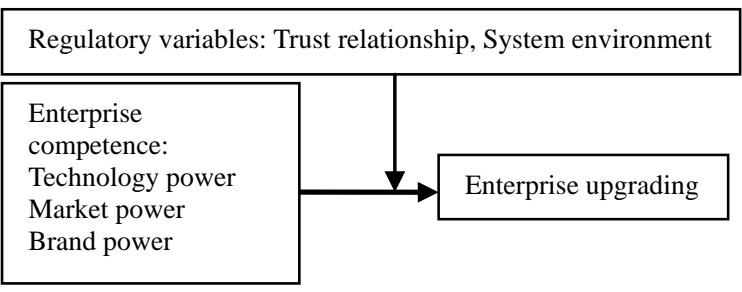

Fig. 1. Study model diagram

\section{B. Measurement of variables}

With reference to the theoretical and empirical research in the fields of enterprise upgrading and enterprise competence, this study designed a relevant research scale. The enterprise survey questionnaires include enterprise competence, trust relationship, system environment and enterprise upgrading, all three aspects, with a total of 54 indicators. The measurement of variables of this study were designed using 7-level subjective perception Likert scale method (Likert scale), 7-level scales and scoring method were chosen to prevent over-skewness in the measurement data.

\section{DATA ANALYSIS AND HyPOTHESIS TESTING}

\section{A. Test of reliability and validity}

The measurement scale of this study is based on collecting the results of relevant researches, combining with interview results to make appropriate changes in the mature scales of existing studies, which to some extent provides better reliability and validity to the measure of the variables. In the meantime, this study uses SPSS 21.0 software to conduct related tests; the results are shown in Table I. First of all, the Cronbach's $\alpha$ values of all dimensions are above 0.800 , showing that the reliability of the scale is at a high level. Therefore, it can be inferred that the questionnaire design is credible. Second, the KMO values in all dimensions of the questionnaire were all above 0.700 , much higher than the lowest standard of 0.500 . The significance of the spherical test in each dimension was observed, and Sig values were all 0.000 highly significant. After factor analysis, the lowest explained variance is $66.714 \%$, higher than the standard of 50\%; After orthogonal rotation, analyze factors in each dimension, by extracting a common factor in each dimension to further observe the load of each dimension factor we can know that, the lowest load is 0.758 , far higher than the lowest standard of 0.300 . According to the test results of the validity analysis, the structural validity of the questionnaire design is completely qualified.

TABLE I. RELIABILITY ANALYSIS RESULTS OF MEASURING TOOLS ( $\mathrm{N}=316)$

\begin{tabular}{|c|c|c|c|c|c|}
\hline Variable type & Item (Outline) & $\begin{array}{l}\text { Cronbach's a } \\
\text { coefficient }\end{array}$ & Variable type & Item (Outline) & $\begin{array}{c}\text { Cronbach's a } \\
\text { coefficient }\end{array}$ \\
\hline \multirow[t]{11}{*}{$\begin{array}{c}\text { Technology } \\
\text { power }\end{array}$} & & 0.914 & $\begin{array}{c}\text { System } \\
\text { environment }\end{array}$ & & 0.942 \\
\hline & Emphasis on intellectual property & 0.908 & & Reduce tax burden on enterprises & 0.921 \\
\hline & $\begin{array}{l}\text { Apply for patents in the field of } \\
\text { expertise }\end{array}$ & 0.912 & & Simplify the process & 0.921 \\
\hline & Competition of technical standards & 0.900 & & $\begin{array}{c}\text { Development of intermediary } \\
\text { organizations }\end{array}$ & 0.942 \\
\hline & Industrial intellectual property system & 0.898 & & $\begin{array}{l}\text { The degree of development of the } \\
\text { product market }\end{array}$ & 0.922 \\
\hline & Related patent federation & 0.902 & & $\begin{array}{l}\text { The degree of development of the } \\
\text { factor market }\end{array}$ & 0.921 \\
\hline & Formulation of industry standards & 0.913 & & Broaden the financing channels & 0.924 \\
\hline & $\begin{array}{l}\text { Leading the introduction of new } \\
\text { products }\end{array}$ & 0.908 & & Tax-free, tax-cut, interest subsidy & 0.916 \\
\hline & Competitive core technology & 0.900 & & $\begin{array}{l}\text { Talent education and training } \\
\text { system }\end{array}$ & 0.924 \\
\hline & Complementary resources & 0.907 & & Technical standards & 0.920 \\
\hline & $\begin{array}{l}\text { Improve production, technological } \\
\text { process }\end{array}$ & 0.916 & & Foster innovative culture & 0.923 \\
\hline \multirow[t]{9}{*}{ Brand power } & & 0.918 & & Performance of legal system & 0.925 \\
\hline & High brand reputation & 0.896 & Trust relationship & $\begin{array}{l}\text { Exchange information and } \\
\text { resources }\end{array}$ & 0.888 \\
\hline & Unified brand positioning & 0.914 & & Carry out cooperation projects & 0.895 \\
\hline & Purchase intention of premium & 0.898 & & Share information and resources & 0.886 \\
\hline & Unique brand image & 0.920 & & $\begin{array}{c}\text { Strictly perform the contractual } \\
\text { duties }\end{array}$ & 0.911 \\
\hline & Brand gets more popular & 0.903 & & Verbal agreements accountability & 0.921 \\
\hline & Leader in product categories & 0.901 & & Timely provision of services & 0.916 \\
\hline & Welcome because of innovation & 0.905 & $\begin{array}{l}\text { Functional } \\
\text { upgrading }\end{array}$ & & 0.948 \\
\hline & Cost-effective products & 0.892 & & R\&D and marketing departments & 0.941 \\
\hline \multirow[t]{4}{*}{ Market power } & & 0.942 & & Product R\&D technology & 0.946 \\
\hline & Market research capacities & 0.929 & & Has core technologies & 0.939 \\
\hline & Matching extent of new products & 0.932 & & New product development & 0.937 \\
\hline & Pricing power & 0.940 & & Product R\&D capacities & 0.940 \\
\hline
\end{tabular}




\begin{tabular}{|c|c|c|c|}
\hline \multicolumn{4}{|c|}{ Cont. to TABLE I } \\
\hline Cooperation, alliance & 0.926 & $\begin{array}{l}\text { Collaborative development of new } \\
\text { products }\end{array}$ & 0.941 \\
\hline Market management innovation level & 0.930 & Promotion department or function & 0.940 \\
\hline Channel leadership status & 0.928 & $\begin{array}{c}\text { The speed of new products } \\
\text { promotion }\end{array}$ & 0.939 \\
\hline Larger market share & 0.928 & Influence on the terminal market & 0.941 \\
\hline $\begin{array}{l}\text { Affect marketing strategies of the } \\
\text { competitors }\end{array}$ & 0.938 & Improve customer satisfaction & 0.943 \\
\hline
\end{tabular}

TABLE II.

REGRESSION ANALYSIS OF THE RELATIONSHIP BETWEEN THE OEM ENTERPRISE’S DRIVING FORCE AND ITS FUNCTIONAL UPGRADING (N = 292)

\begin{tabular}{|c|c|c|c|c|c|c|c|c|c|}
\hline & Model 1 & Model 2 & Model 3 & Model 4 & Model 5 & Model 6 & Model 7 & Model 8 & Model 9 \\
\hline Constant term & $59.854 * * *$ & $64.332 * * *$ & $64.332 * * *$ & $59.840^{* * *}$ & $59.196 * * *$ & $59.736 * * *$ & $61.314^{* * *}$ & $59.985 * * *$ & $59.957 * * *$ \\
\hline \multicolumn{10}{|l|}{ Control variables } \\
\hline Enterprise type & .366 & .251 & -.146 & .318 & .390 & -.085 & .129 & .138 & .064 \\
\hline \multicolumn{10}{|l|}{ Predictive variables } \\
\hline Technology power & $.783^{* * *}$ & & & $.431^{* * *}$ & & & $.391 * * *$ & & \\
\hline Market power & & $1.006^{* * *}$ & & & $.768^{* * *}$ & & & $.641^{* * *}$ & \\
\hline Brand power & & & $1.141^{* * *}$ & & & $.679 * * *$ & & & $.585^{* * *}$ \\
\hline \multicolumn{10}{|l|}{ Regulatory variables } \\
\hline Trust relationship & & & & $.760^{* * * *}$ & $.417 * *$ & $.698^{* *}$ & & & \\
\hline $\begin{array}{c}\text { Technology power * Trust } \\
\text { relationship }\end{array}$ & & & & .002 & & & & & \\
\hline $\begin{array}{c}\text { Market power * Trust } \\
\text { relationship }\end{array}$ & & & & & $.015^{* * * *}$ & & & & \\
\hline $\begin{array}{l}\text { Brand power * Trust } \\
\text { relationship }\end{array}$ & & & & & & $.021 * * *$ & & & \\
\hline System environment & & & & & & & $.421^{* * * *}$ & $.296^{* *}$ & $.405^{* * * *}$ \\
\hline $\begin{array}{c}\text { Technology power * System } \\
\text { environment }\end{array}$ & & & & & & & $.028^{* *}$ & & \\
\hline $\begin{array}{c}\text { Market power * System } \\
\text { environment }\end{array}$ & & & & & & & & $.002 * *$ & \\
\hline $\begin{array}{c}\text { Brand power * System } \\
\text { environment }\end{array}$ & & & & & & & & & .004 \\
\hline \multicolumn{10}{|l|}{ Model Statistics } \\
\hline $\mathrm{R}^{2}$ & .689 & .818 & .748 & .808 & .832 & .801 & .880 & .854 & .843 \\
\hline $\mathrm{R}^{2}$ after adjustment & .678 & .812 & .739 & .794 & .820 & .786 & .871 & .843 & .831 \\
\hline Statistics & $62.014^{* * *}$ & $126.067 * * *$ & $83.018^{* * *}$ & $56.871^{* * *}$ & $67.072 * * *$ & $53.232 * * *$ & $99.210^{* * *}$ & $\begin{array}{c}79 . \\
123^{* * *}\end{array}$ & $71.111^{* * *}$ \\
\hline Conclusion & Obvious & Obvious & Obvious & $\begin{array}{c}\text { Not } \\
\text { obvious }\end{array}$ & Obvious & Obvious & Obvious & Obvious & $\begin{array}{c}\text { Not } \\
\text { obvious }\end{array}$ \\
\hline Assumption & Valid & Valid & Valid & Invalid & Valid & Valid & Valid & Valid & Invalid \\
\hline
\end{tabular}

\section{B. Correlation analysis}

All variables were correlated and all were significantly correlated at $\mathrm{P}<0.05$ and above, confirming the rationality of previous hypotheses.

\section{Test results}

This paper draws on the analytical methods of the regulatory variables of Wen Zhonglin et al. (2005) to study the regulatory role of trust relationship and system environment on the driving force and functional upgrading of the OEM enterprises. According to the previous research assumptions, nine test models are established accordingly. The test results of the models are shown in Table II, and then the significance of the regulating effect is judged according to the trend of sig value and R2 value of the test results. According to Table II, the influence of the control variable "enterprise type" on the dependent variable "functional upgrading” is not significant.

\section{CONCLUSION}

This study discusses the issues of OEM enterprises' independent innovation and brand creation from the perspective of enterprise powers. In practice, the OEM enterprises would also seek upgrading strategies actively, but they are under huge pressure and facing the unpredictability of the future, so they are lacking of confidence in implementing the strategies.

\section{A. The regulatory role of trust relationship on the driving} force and functional upgrading of the OEM enterprises

The influence of OEM enterprises' technology power, market power and brand power on the upgrading of enterprise functions is regulated by the trust relationship between the enterprises and their network members. In-depth study found that the significance of regulatory role of the trust relationship is different from the attribute of driving force. The influence of trust relationship on the technology power and the foundries' functional upgrading is not obvious. For the OEM enterprises, it's necessary to distinguish the imitation technologies from the independent technological innovation; their difference is in establishing broader trust relationship network, not limited to the trust and dependence on the technical aspects of multinational corporations. The influence of trust relationship on the market power, the brand power, and the foundries' functional upgrading is significant. The trust relationship can alter the communication context between the OEM enterprises 
and their partners, so as to help them obtaining more information for their functional upgrading. As business functions continue to improve, the customer loyalty and brand awareness are increasing, the foundries would have more opportunities to cooperate with better external resources and to attract excellent technologies and marketing talents, the regulatory role of the trust relationship will be reflected in the upgrading of enterprises from many aspects.

\section{$B$. The regulatory role of system environment on the driving force and functional upgrading of the OEM enterprises}

This study confirms that the system environment can regulate the influence of the driving force and functional upgrading of the OEM enterprises. The establishment of system environment comes from the law, culture, economy, politics, science and technology, finance and other aspects, which is three-dimensional management from the state to the local government. In an unstable external environment, the system environment is of particular importance. Appropriate system environment can provide the OEM enterprises with upgrading conditions and direction guidance, and it can reduce the resistance of enterprises upgrading; narrow the gap with multinational corporations. Enterprises with a strong desire to upgrade are more dependent on the system; they take the initiative to make use of the favorable factors of the system environment to shape their competence, and the role of system environment changes from pulling force to the driving force. The government would also change the upgrading willingness of the enterprises by altering the systems, so as to promote the implementation of relevant policies more efficiently than expected.

\section{ACKNOWLEDGMENT}

This work is supported by Innovation and Entrepreneurship Course of Nanchang Hangkong University, Research Project on Teaching Reform of Jiangxi Higher Institutions in 2018 (JXJG-18-8-8): "Modern Sales Practice" Course Reform Design and Application Effect Research, Jiangxi Provincial Education Science 13th Five-Year Plan(18YB135).

\section{REFERENCES}

[1] Kaplinsky, R., Morris, M. "The globalization of product markets and immiserizing growth: Lessons from the South African furniture industry," World Development, Vol.30, No.7, pp.1159-1177, 2002.

[2] Mei, L. C. "Power concentration, production fragmentation, and local upgrading in the global value chains,” Human Geography, No.4, pp.32-37, 2009.

[3] Kang, K., Wei, X. G. "The Influence of Technology Power on Competitive Advantage in Global Value Chain: The Mediation and Moderation Effects of Radical Innovation," Science of Science and Management of S. and T., Vol.37, No.3, pp.116-124, 2016.

[4] Asaftei, G., Parmeter, C. F. "Market power, EU integration and privatization: The case of Romania,” Journal of Comparative Economics, Vol.38, No.3, pp.340-356, 2010.

[5] Kamal, S. "market power in the global economy: the exhaustion and protection of intellectual property," The Economic Journal, Vol.123, No.3, pp.131-161,2012.

[6] Lin, L., Zeng, G. “A review on technical powers in enterprise networks," World Development, Vol.123, No.3, pp.16-19,61,2010.

[7] Brandow, G. E. "Market Power and its sources in the Food Industry," American journal of Agricultural Economies, Vol.51, No.1, pp.1-12, 1969

[8] Liu, Z. B., Zhang, J. "Forming, Breakthrough and Strategies of Captive Network in Developing Countries at Global Outsourcing System: Based on a Comparative Survey of GVC and NVC," China Industrial Economy, No.5, pp.39-47, 2007.

[9] Patrick, B. "Brand equity: Snark or boojum?,” International Journal of Research in Marketing, Vol.10, No.1, pp.93-104,1993.

[10] Temi, A. "Branding as a Competitive Strategy for Demand Management in SMEs," Journal of Research in Marketing and Entrepreneurship, Vol.3, No.2, pp.97-106, 2001.

[11] Daniel, J. M. “Affect and Cognition-Based Trust as Foundation for Interpersonal Cooperations,” Academy of Management Journal, Vol.38, No.1, pp.24-59, 1995.

[12] Bart, N. "Trust, Opportunism and Governance: A Process and Control Model,” Organization Studies, Vol.17, No.6, pp.985-1010, 1996.

[13] Wang, Z. N., Wu, Y. Y., Ye, X. F. "Empirical Study on Influencing Factors of the Intention of Knowledge Flow in Virtual S \& T Innovation Team-Based on the Analytical Framework of Knowledge Network,” R \& D Management, Vol.24, No.2, pp.47-57, 2012.

[14] Li, S. T., Qu, W. N. "Political connections, institutional environmen and R\&D expenditure,” Science Research Management, Vol.36, No.4, pp.56-64, 2015. 